\title{
OUTRAS IDEIAS SOBRE A GESTÃO UNIVERSITÁRIA
}

Autores: Aline de Oliveira Gonçalves, jornalista; William Leal Colaço

Fernandes, coordenador da Seção de Comunicação do Setor Litoral Colaboração: Maximiliano Stersa Budke, coordenador administrativo do Setor Litoral

O corpo técnico-administrativo das instituições públicas de ensino superior tem, em geral, pouca visibilidade dentro e fora da comunidade acadêmica. Os profissionais que exercem essas funções, quando informam que trabalham em uma universidade, quase sempre ouvem a pergunta: você é professor de que área? Ou seja, poucos cidadãos se dão conta que, para a estrutura educacional existir, são necessários outros profissionais, além dos docentes.

O reconhecimento e a valorização das carreiras técnico-administrativas passam por diversos processos políticos e técnicos em âmbito nacional, mas também de ações locais. Essas ações precisam equilibrar a ascensão lenta da carreira, a falta de estrutura disponível para exercer o trabalho e momentos de desgastes políticos e econômicos podem gerar desmotivação nos servidores.

Assim, no ambiente universitário se faz necessário um modelo de gestão diferenciado e adaptado à realidade e à cultura da organização local, visando sempre a qualidade da prestação do serviço público, com eficiência, eficácia e efetividade. As políticas de gestão de cada universidade, ou mesmo, de setores dentro dessas, podem gerar perspectivas diferentes para o seu corpo técnicoadministrativo.

Nesse sentido, a gestão administrativa do Setor Litoral da Universidade Federal do Paraná possui algumas características singulares, que serão abordadas neste artigo. O projeto litoral foi implantado em 2004, resultado de uma parceria das três instâncias de governo: federal, estadual e municipal, primeiramente como campus da UFPR e posteriormente se tornou um Setor. De acordo com o Projeto Político Pedagógico do Setor Litoral, a proposta de sua implantação teve como objetivo "representar mais do que a ampliação de vagas no ensino superior (...), mas instalou um Projeto inovador em uma região 
geográfica desacreditada historicamente e com uma grande debilidade econômica" (UFPR, 2008). Esse projeto também pressupõem o envolvimento de todos os atores educacionais na sua construção e desenvolvimento. Assim, há uma perspectiva, ainda em construção, de que o papel da equipe técnicoadministrativa vá além do cumprimento de processos burocráticos e do atendimento das demandas do público interno e externo. Cada profissional, dentro de suas habilidades e possibilidades, pode vir a buscar espaços para se envolver com a formação e o aprimoramento dos processos organizacionais.

Tendo isso como horizonte, a forma como estão estruturadas as seções administrativas, é resultado de um longo processo de aproximações entre as demandas institucionais e a disponibilidade de servidores, seja por suas formações acadêmicas ou interesses profissionais. O Grupo de Estudos e Trabalho dos Técnicos (Gtest), espaço aberto a todos os servidores e que promovia encontros semanais para a troca de experiências e construções conjuntas, foi uma das iniciativas que contribuiu para que se chegasse ao atual desenho das Seções Administrativas.

O objetivo de se criar, através de um modelo de gestão inovador, um clima organizacional mais solidário, é a melhora da qualidade do atendimento, da qualidade de vida e do desempenho pessoal e organizacional. "Não há dúvida de que a motivação positiva fundamental é aquela relacionada com o sentido de missão do servidor" (CHIAVENATO, 2016). Visa-se também ambientes adequados à inovação e uma qualificação intensiva das equipes de trabalho, gerando assim servidores multifuncionais e não somente especialistas, agregando valor ao profissional e consequentemente, criando um ambiente propício para a melhora do desempenho da organização (VASCONCELOS et al., 2009).

Implantar um sistema inovador não é uma tarefa simples, pois transpassa temas como o clima e a cultura organizacional que estão enraizados em qualquer organização. Para superar esse ponto, se fez necessário melhorar as relações de trabalho e a comunicação interna da organização, para enfrentar os problemas diários. 
Atualmente, o Setor Litoral conta com uma equipe de 231 servidores, desses 95 são técnico-administrativos em educação. A distância da sede (em Curitiba) e as características do público atendido (a maioria dos estudantes são jovens adultos, oriundos de escolas públicas e tem renda familiar baixa), faz como que haja necessidade de profissionais que atendam demandas específicas do local. Devido a esses atributos, o Setor conta com uma equipe integrada por assistentes sociais, psicólogos, médicos, enfermeiros e também profissionais das áreas de gestão como administradores, secretários executivos, contadores, analistas de sistemas, entre outros.

Os técnico-administrativos estão lotados em duas grandes áreas, a coordenação acadêmica e a coordenação administrativa. Sendo que a primeira é composta pelas seguintes seções: Gestão Acadêmica; Políticas Afirmativas, Assuntos Estudantis e Comunitários (Sepol); Gestão Pedagógica; Gestão de Laboratórios Didáticos; e Apoio à Biblioteca e Documentação. A política dessa grande área é dar o apoio necessário para que estudantes e docentes possam exercer seus papéis no âmbito universitário, seja no suporte a gestão dos cursos até o apoio psicossocial àqueles que necessitam.

A coordenação administrativa é composta pelas seções: Gestão de Pessoas; Serviços de Apoio Administrativo; Execução Orçamentária; Tecnologia da Informação; Comunicação e eventos; e Arquitetura. Nela, os profissionais dão suporte para o exercício pleno das atividades acadêmicas e administrativas, além da execução orçamentária e relacionamento com a comunidade do entorno.

Atualmente, a Coordenação Administrativa atua em uma gestão com enfoque participativo, primando pela valorização dos profissionais que atuam nas seções a ela subordinadas, aliando o conhecimento teórico ao prático, na busca do aumento na qualidade dos serviços prestados aos usuários e proporcionado um maior bem-estar da equipe. A proposta dessa estrutura é proporcionar ao servidor autonomia para ajudar a escrever a história da organização, sentindo-se comprometido e valorizado, diante suas competências.

Portanto, para se alcançar a melhora da administração pública e consequentemente a melhora do serviço público, é necessário investimento nos 
servidores, em sua capacitação e em seu desenvolvimento pessoal. Pois os servidores técnico-administrativos são fundamentais para a mudança organizacional e a sua participação essencial para uma instituição com o porte e a projeção da UFPR.

\section{REFERÊNCIAS}

CHIAVENATO, Idalberto. Administração geral e pública: provas e concursos. 4. ed. Barueri, SP: Manole, 2016.

VASCONCELOS, Katia Cyrlene de Araujo; MERHI, Danielle Quintanilha; DA SILVA JUNIOR, Annor; MARTINS DA SILVA, Priscilla de Oliveira. Cultura, liderança e compartilhamento do conhecimento organizacional. Revista de Administração Faces Journal, Belo Horizonte, v. 12, n. 1, p. 13-31, jan./mar. 2013. Disponível em:

<http://www.fumec.br/revistas/facesp/article/view/1163/1205>. Acesso em: 18 out. 2017.

UNIVERSIDADE FEDERAL DO PARANÁ. Projeto Político Pedagógico da UFPR Litoral. Matinhos, 2008, 55p. Disponível em: <http://www.litoral.ufpr.br/ portal/ufpr-litoral/projeto-politico-pedagogico/>. Acesso em: 18 out. 2017. 